\title{
"Boa noite, bom dia HUAP!", uma experiência de humanização na formação de profissionais da área de saúde*
}

\author{
Pedro Gemal Lanzieri ${ }^{1}$ \\ Lenita Barreto Lorena Claro ${ }^{2}$ \\ Fernando Cesar Ranzeiro de Bragança ${ }^{3}$ \\ Vera Regina dos Santos Montezano ${ }^{4}$ \\ Célia Sequeiros da Silva ${ }^{5}$
}

\section{Introdução}

Entre os problemas da atenção à saúde que a Política Nacional de Humanização, do Ministério da Saúde, propõe-se a enfrentar, estão: a "fragmentação do processo de trabalho e das relações entre os diferentes profissionais", a "precária interação nas equipes e despreparo para lidar com a dimensão subjetiva nas práticas de atenção", e um "modelo de atenção centrado na relação queixa-conduta". Entre os componentes do conceito de humanização, expressos por essa política de saúde, estão: a valorização dos diferentes sujeitos implicados no processo de produção de saúde, enfatizando sua autonomia, corresponsabilidade, o estabelecimento de vínculos solidários e a participação coletiva nos cuidados em saúde; o incentivo à união e à colaboração interdisciplinar de todos os envolvidos, dos gestores, dos técnicos e dos funcionários, assim como a organização para a participação ativa e militante dos usuários nos processos de prevenção, cura e reabilitação (Brasil, 2004, p.11-3).

Nos debates sobre a formação de profissionais de saúde e nas diretrizes curriculares dos cursos da área de saúde, a humanização e a integralidade da atenção têm sido temas relevantes (Rego et al., 2008; Souza, Moreira, 2008; Koifman, 2001). O trabalho em saúde e a formação de seus profissionais pressupõem aspectos técnicos e relacionais, a busca da "cura" e o "cuidado" dimensões estas que ainda são vistas como separadas, dicotômicas, em paralelo à dicotomia entre corpo e mente/alma (Ferreira, 2005). A dimensão da cura, envolvendo conhecimentos e habilidades técnicas, é priorizada nos currículos profissionais, especialmente dos médicos. Superar essa dicotomia e mesclar, à técnica, a dimensão relacional, "humana", é um desafio que se coloca nos currículos de graduação e nas políticas e práticas de saúde (Ayres, 2004).

As reformas curriculares têm procurado responder a essa questão, incorporando o ensino das ciências sociais e das humanidades. Esse ensino destina-se ao desenvolvimento de habilidades e atitudes, tais como a comunicação, a empatia, a solidariedade e o acolhimento, as quais capacitam o estudante a desenvolver uma relação mais próxima, ética e satisfatória, tanto com clientes, quanto com outros profissionais (Turini et al., 2008; Ruiz-Moral, 2007; Sucupira, 2007). A introdução de saberes inovadores no campo da saúde, como as artes, também atende a essa finalidade, entre outras (Ayres, 2005; Tapajós, 2002).

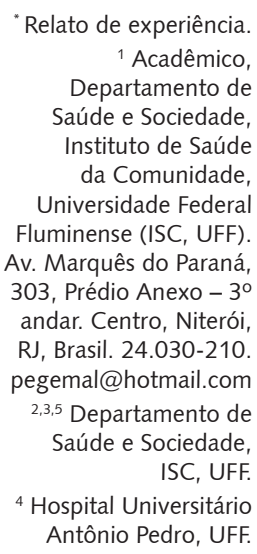


Outra questão preocupante na formação desses futuros profissionais é a dificuldade encontrada para integrá-los por meio de seus currículos, com a finalidade de promover maior convivência, troca de conhecimentos e respeito ao saber alheio, e facilitar o aprendizado do trabalho em equipe (Souza, Moreira, 2008; Garcia et al., 2007; Saupe, Budó, 2006).

Os projetos de extensão universitária têm se revelado como instrumentos pedagógicos importantes ao propiciarem essa desejada integração multiprofissional, o desenvolvimento da dimensão relacional e a prestação do "cuidado" na formação dos estudantes da área da saúde, por meio de atividades práticas (Saraiva, 2007; Hennington, 2005).

O projeto "Boa noite, bom dia HUAP!" nasceu da proposta do acadêmico de Medicina da UFF, Rodrigo Mello Ferreira, apresentada na disciplina Iniciação Científica. Tornou-se um projeto de extensão universitária no início de 2008 e, desde então, tem sido coordenado por professores do Departamento de Saúde e Sociedade, que compõe o Instituto de Saúde da Comunidade da UFF. Atualmente, participam, como profissionais, dois professores desse departamento, com formação médica, uma terapeuta ocupacional, do mesmo departamento, e uma enfermeira do Hospital Universitário Antônio Pedro (HUAP), com pós-graduação em arteterapia.

\section{Objetivos}

A finalidade do presente trabalho é avaliar a contribuição do projeto de extensão "Boa noite, bom dia HUAP!" à formação humanística dos estudantes da área de saúde, por intermédio dos significados atribuídos pelos mesmos a essa experiência.

Os objetivos do projeto são:

a) Contribuir para a formação humanística dos estudantes da área de saúde, possibilitando maior integração entre estudantes de diferentes cursos e a aquisição de: competências comunicacionais, sensibilidade estética, capacidade para exercer o cuidado e para melhor lidar com a afetividade envolvida nas relações entre profissionais e clientes, por intermédio de atividades práticas.

b) Contribuir para a recuperação da saúde e melhoria da qualidade do período de hospitalização de clientes do HUAP por meio do diálogo entre estudante e cliente e do compartilhamento de atividades lúdicas criativas.

\section{Método}

O público-alvo do projeto são os estudantes de cursos de graduação na área de saúde e a clientela hospitalizada. O público atingido indiretamente é formado por acompanhantes, visitantes e familiares dos pacientes, assim como funcionários do HUAP.

Atualmente, conta-se com cerca de cinquenta estudantes, com predomínio dos cursos de medicina e enfermagem. Participam, também, estudantes de farmácia, psicologia, serviço social e de outros cursos de graduação. Conta-se, ainda, com um aluno bolsista de extensão. Alguns estudantes integram o projeto desde sua criação, a maioria permanece vinculada ao mesmo durante um ou dois semestres.

Os participantes são divididos em grupos, coordenados por um profissional de saúde ou docente, e realizam visitas semanais a enfermarias do HUAP, no horário de $18 \mathrm{~h} 30$ às vinte horas, sendo feita a preparação e organização da visita nos trinta minutos que a antecedem. O projeto dispõe de fantasias, adereços, instrumentos musicais, materiais gráficos e expressivos diversos. Faz-se ainda uso de dobraduras (origami) e jogos (de tabuleiros, memória etc). A interação entre estudantes e clientela é estimulada por meio de conversas, escuta e de atividades que são propostas. A música, assim como outras atividades lúdicas (mágicas, fantoches, brincadeiras, palhaçaria etc.), complementam as intervenções.

Semanalmente, um grupo se reúne para estudo de artigos e textos sobre temas afins ao projeto. Periodicamente, os participantes de todos os grupos se reúnem para avaliar, discutir as estratégias 
e atividades realizadas e sugerir novas abordagens. Oficinas de capacitação são promovidas para favorecer e aprimorar o desenvolvimento de habilidades artísticas e comunicativas. Além disso, desenvolvem-se projetos de pesquisa, dando oportunidade de participação a alunos interessados na Iniciação Científica, que é uma atividade optativa nos currículos.

O projeto dispõe de página na internet e um e-mail de grupo, que permitem maior agilidade na divulgação das atividades e comunicação entre os participantes. A participação dos estudantes neste projeto de extensão é opcional (não recebem créditos curriculares), embora recebam certificados de participação. Como a carga horária dos currículos na saúde é muito extensa, o tempo e a disponibilidade para atividades de extensão são restritos, o que desestimula a inserção de muitos estudantes e limita o número de horas semanais que podem ser solicitadas de participação. Assim, não tem sido possível discutir com todos os estudantes, em profundidade, após as visitas, as vivências ocorridas. Optou-se, então, por se compartilhar as impressões sobre essas experiências através do e-mail de grupo.

Após cada visita dos grupos às enfermarias, pede-se que um dos estudantes elabore um relatório das atividades realizadas, situações, experiências e sentimentos vivenciados. Outros estudantes são estimulados a contribuir com o "diário", acrescentando suas impressões. Esses "diários" são compartilhados através do "e-mail de grupo", ficando disponíveis para todos consultarem, bem como as "respostas" de alguns dos demais participantes, ou seja, a reação que expressaram à leitura. Foi solicitada, dos autores de diários, sua autorização para a utilização dos mesmos para avaliação das atividades do projeto, sendo, neste caso, preservado seu anonimato.

Utilizou-se a metodologia qualitativa para analisar o material composto pelos diários produzidos desde o início das atividades do projeto, por intermédio da análise de conteúdo, na modalidade temática, e realizada uma leitura compreensiva do conjunto do material, seguida de sua categorização e interpretação (Pope, Mays, 2009; Minayo, 2006).

\section{Resultados e discussão}

Da observação do conjunto de diários das visitas, destacam-se três temas principais: as dificuldades dos estudantes em lidarem com a afetividade envolvida na interação com os clientes; a oportunidade de interagirem com os clientes de forma diferenciada; os efeitos benéficos percebidos como resultantes desses encontros, tanto para os clientes quanto para os estudantes. Esses temas são discutidos a seguir, sendo ilustrados com trechos reproduzidos dos diários.

\section{Dificuldades para lidar com a afetividade}

A formação do profissional de saúde, especialmente do médico, no modelo da medicina ocidental, envolve, prioritariamente, a aquisição de conhecimentos e habilidades técnicas que pressupõe a utilização da racionalidade e objetividade, características da ciência moderna. A dicotomia razão X emoção, e a superioridade da primeira sobre a segunda, orientam essa formação, durante a qual é estimulado o uso da razão em detrimento das emoções, resultando em obscurecimento dos sentimentos e dos afetos, com consequente distanciamento emocional do cliente.

Nos diários analisados, a dificuldade dos estudantes para lidarem com a afetividade - aqui entendida como o conjunto de emoções e sentimentos - tornou-se evidente. Alguns diários assemelham-se a um relato impessoal, descritivo, das atividades realizadas. A dificuldade em aproximar-se, em abordar os clientes, em estar ali, numa enfermaria do hospital, num papel diferente do esperado para um estudante da área da saúde, foi observada em muitos relatos. Outras vezes, a emoção aflorada nos encontros promoveu embaraço e tentativas de ocultação da mesma:

\footnotetext{
"Combinamos que entraríamos na ala infantil cantando uma música e assim o fizemos. As crianças olharam meio assustadas, nem deram muita atenção. Resolvemos parar de cantar. Bateu um desespero enorme nessa hora, não tinha a menor idéia do que dizer a elas. [...]
} 
"BOA NOITE, BOM DIA HUAP!", UMA EXPERIÊNCIA DE HUMANIZAÇÃO...

pediram para irmos à ala dos pacientes com problemas no coração e isso gerou uma nova tensão, porque não seriam mais crianças...". (estudante de psicologia, $4^{\circ}$ período)

"[...] chegou a hora e tivemos que nos despedir. Seu E. estava visivelmente emocionado, com direito a sinceras lágrimas. Eu e A. nos seguramos para não chorar também". (estudante de medicina, $3^{\circ}$ período)

Destacaram-se os relatos de dificuldades para lidar com o sofrimento do outro, especialmente com os pacientes com doenças graves, ou com a morte:

"Fiquei muito apreensiva quando soube que iríamos à hematologia, sem dúvida um desafio para mim, tendo em vista meu cansaço, principalmente mental. Assim que chegamos na enfermaria nos deparamos com Dona S. que não gostou muito da idéia de cantarmos por lá. Houve, por alguns minutos, um silêncio profundo por parte de nós que atentamente escutávamos sua justificativa. Ela estava muito enjoada, pois acabara de sair de uma sessão de quimioterapia, passando muito mal. [...] Que momento de agonia, não sabíamos muito o que fazer, apenas ouvíamos ela balbuciar pedindo ajuda e forças à Deus enquanto vomitava. No momento, assim como ela, apenas consegui balbuciar que tudo ia ficar bem, que ela ia melhorar, que tudo aquilo ia passar. Mas, por Deus!! Que angústia no meu coração naquele momento!". (estudante de medicina, $3^{\circ}$ período)

“Íamos percorrendo os leitos, e eu continuava acompanhando o aparelho da paciente crítica. F. resolveu cantar para ela, e descobrimos que seu nome era T. Conforme F. falava, ela acenava com a cabeça. Parecia concordar com a gente. Antes de sairmos, olhei o aparelho uma última vez: ele mostrava '10'. Quando saímos da sala, ela faleceu. Descemos em silêncio, até que alguém disse algo do tipo "Caramba, ela morreu!" Minha cabeça estava a mil: o que era pra ser uma visita simples se tornou numa experiência sem igual. Não sabia o que dizer, não tinha o que dizer. Aquelas pessoas percorriam minha mente incessantemente. As macas, a enfermagem, as fantasias, as bolhas de sabão, as crianças, a T...". (estudante de psicologia, $4^{\circ}$ período)

"Cheguei ao CTI e me sentei ao lado dela, olhando a cama, pensando no nada [...] A mãe de R. entrou, pedi desculpa pela invasão e a abracei. [...] Chorei, claro. Ali estava a mesma R. que quis tirar mil fotos com acessórios, que brincou com as bolas de sabão, que cantou com um grupo enorme numa sexta lá na hematologia. Só que havia somente o barulhinho do respirador, uma menina que teve as unhas compridas cortadas, as enfermeiras conversando no balcão. Despedi-me perguntando se poderia voltar no dia seguinte, um pouco mais cedo por causa da aula que teria depois. [...] Foi difícil acordar cedo no dia seguinte, mas lembrei que ela estava me esperando. Cheguei cedinho. O aparelho apitava de maneira diferente. Não sabia o que tinha acontecido, mas sabia que R. tinha piorado. Fiquei parada, meio sem saber o que fazer. O médico analisando, ouvindo, palpando... Saí quando precisei ir pra aula. Já estava até atrasada. Sabia que R. tinha piorado, sabia que era inevitável, mas ainda sim, mesmo sem ter parentesco nenhum, mesmo só a tendo visto uma vez, era doloroso, era triste. Não fui ao BNBD naquela quarta-feira, mas também não chegaríamos a tempo. R. morreu à tarde. Eu fiz o que poderia ter feito: conversado, dado carinho. E percebi como a prática médica (e da saúde) é difícil, como nos é exigido domínio das emoções e racionalidade. Senti-me como se tivesse perdido uma paciente, e mal comecei minha estrada num hospital". (estudante de medicina, $1^{\circ}$ período)

Experiências como essas, de compartilhar momentos de dor e de vivenciar o sofrimento com a morte de um paciente que se tornou muito próximo, ao mesmo tempo em que trazem para o estudante desconforto ou tristeza, são consideradas por este como sumamente importantes para sua formação. 
Em geral, a disciplina de anatomia é que proporciona o primeiro contato do estudante com a morte, uma morte despersonalizada, sem identidade e sem história (Sadala, Silva, 2008), com a qual o estudante deve lidar de forma objetiva, reprimindo as emoções. Durante a formação, o estudante é estimulado a manter o distanciamento emocional em relação à morte e conta com pouco apoio para lidar com as questões emocionais envolvidas. O tema é discutido em algumas disciplinas, como psicologia médica, porém de forma teórica, e o aprendizado prático por meio do convívio com médicos, nos anos mais avançados do curso, frequentemente se contrapõe ao que foi aprendido em sala de aula.

A noção comum, do profissional de saúde como alguém que evita a morte e salva vidas, resulta em sentimentos de frustração e impotência diante de pacientes terminais. A oportunidade de conviver com essa clientela, conhecendo-a melhor e possibilitando novas formas de ajuda, além do saber técnico, colabora para que se formem profissionais que saibam cuidar de pessoas mesmo quando consideradas tecnicamente "incuráveis".

\section{Encontros estudantes-clientes}

Apesar das dificuldades observadas para a interação, na maior parte dos diários aparece a gratificação dos estudantes por terem conseguido estabelecer vínculos mais próximos com alguns dos pacientes, por poderem conhecê-los melhor, não como portadores de um problema de saúde, mas como pessoas com uma rica e variada bagagem de vida:

"[...] fui tocar para o senhor ao lado, o qual me recebeu muitíssimo bem. Após tocar, começamos a conversar e acabei ficando por ali até o momento de ir embora. Ele me falou de sua família, seu trabalho, e de sua fé. Ele me desejou tantas coisas boas, as quais nem saberei mais detalhar. O que sei é que saí de lá com a vontade de retornar no dia seguinte". (estudante de medicina, $1^{\circ}$ período)

"Assim que chegamos pertinho e começamos a conversar com ele enquanto o pessoal fazia a festa do outro lado, descobrimos que ele era cego há alguns anos! Antes disso, nos enrolamos no portunhol para engrenar a conversa porque o sotaque dele parecia meio que de argentino, depois ele revelou que é peruano e está no Brasil acho que desde seus oito anos, portanto é mais brasileiro que peruano. Foi um bate-papo muito animado descobrimos que ele é um artista multifacetado! Artes plásticas, cênicas... Vai desde um simples professor de espanhol, até um cantor de bolero!!!". (estudante de medicina, $3^{\circ}$ período)

O convívio entre clientes e estudantes permite que estes exercitem a capacidade de se comunicarem, a habilidade de ouvir, compreender o outro de uma forma mais ampla e ser por este compreendido, estabelecendo relações mais próximas e afetivas, as quais, em alguns casos, permanecem mesmo depois da alta hospitalar.

\section{Efeitos das interações}

A percepção de efeitos benéficos desses encontros, não só para os clientes e seus acompanhantes, mas também para si próprios, foi destacada em muitos relatos dos estudantes:

“Todos nós estávamos muito animados, porém tivemos um imprevisto que nos deixou constrangidos. No segundo box que entramos, encontramos uma paciente com depressãopós-parto. Ela não falava, e conforme cantávamos ela fazia caras de dor e se contorcia. Não lembrava seu nome e nem conseguia passar para nós o que ela sentia. Alguns de nós saímos e fomos continuar a visita. Outros ficaram conversando com aquela paciente. Sua companheira de box até disse 'Gente, chamem a enfermeira, vocês conseguiram um milagre. Ela não fala com ninguém e está conversando com vocês!'". (estudante de enfermagem, $4^{\circ}$ período) 


\begin{abstract}
“Primeiro, foi muito gratificante ver a calma dos lactentes após algumas músicas que tentei tocar na flauta. Ainda não estou muito boa, mas tenho me esforçado e acho que as crianças captam meu carinho e me retribuem de uma maneira inexplicável [...] Após um tempinho, voltei para a enfermaria dos lactentes e uma mãe fez a seguinte observação: 'depois que você saiu ele começou a chorar'. Então voltei a tocar flauta e ele se acalmou". (estudante de medicina, $1^{\circ}$ período)
\end{abstract}

\footnotetext{
"Na última sexta-feira, chegando numa das enfermarias, uma senhora me olhou com olhar de dor. Num primeiro momento me senti impotente e sem ação. De repente, percebi que somente meus ouvidos seriam suficientes naquele momento e que nada a mais poderia surtir o mesmo efeito que tal atitude. Um semblante de alívio surgiu na face dela e eu não conseguia entender ainda o motivo. Foi quando ela me deu um abraço, um abraço tão cheio de verdade que pouca ou nenhuma vez senti". (estudante de farmácia, $9^{\circ}$ período)
}

Estar hospitalizado é ser despojado temporariamente de uma complexa identidade social para adquirir a identidade limitada e passiva de doente (Sant'Anna, 2000; Toralles-Pereira et al., 2004). As atividades propostas pelo projeto destinam-se a ajudar o estudante a acessar e comunicar-se com a essência saudável daquele que está, temporariamente, desempenhando o papel de doente. Esse contato especial entre estudante e cliente pode ser compreendido, com base na obra do filósofo Espinoza (2009, p.1677), como "bons encontros", pois elevam o grau de potência de ambos os lados e produzem bons efeitos, tais como a alegria. Para Espinoza, não há oposição entre razão e emoção, e esta é fundamental para se conhecer o outro.

\title{
Reflexões finais
}

Almeja-se, que, ao final do curso de graduação, tenha-se um profissional de saúde mais humano, capacitado para o cuidado integral. Os "campos de significado" propostos por Phenix (Tapajós, 2008), como as seis áreas básicas da educação, incluem: o campo simbólico, voltado para a comunicação; o campo estético, voltado para a singularidade da experiência, e o campo sinoético, que abrange o conhecimento de si e do outro, a introspecção e a conscientização (Tapajós, 2008). A formação profissional nesses campos requer o investimento em estratégias pedagógicas que privilegiem a experiência, considerada fundamental nas palavras do educador Bondía (2002, p.24):

A experiência, a possibilidade de que algo nos aconteça ou nos toque, requer um gesto de interrupção, um gesto que é quase impossível nos tempos que correm: requer parar para pensar, parar para olhar, parar para escutar, pensar mais devagar, olhar mais devagar, demorar-se nos detalhes, suspender o juízo, suspender a vontade, suspender o automatismo da ação, cultivar a atenção e a delicadeza, abrir os olhos e os ouvidos, falar sobre o que nos acontece, aprender a lentidão, escutar aos outros, cultivar a arte do encontro, calar muito, ter paciência e dar-se tempo e espaço.

Este autor nos chama a atenção para o fato de que a experiência é cada vez mais rara pelo excesso de informação, pelo excesso de opinião, pela falta de tempo e pelo excesso de trabalho. O saber da experiência se dá na relação entre o conhecimento e a vida humana e traz, em si, a capacidade de formação ou de transformação (Bondía, 2002) Nos cursos de graduação na área da saúde, a ênfase na aquisição de conhecimentos técnicos, que se multiplicam de forma acelerada, deixa poucos espaços (internos e externos) para a aquisição do saber da experiência. Projetos de extensão universitária, como o "Boa noite, bom dia HUAP!", permitem abrir esses espaços.

Entre as limitações do projeto está o curto período em que o estudante participa semanalmente das atividades, tendo em vista o excesso de exigências curriculares a que é submetido. Ainda assim, consideramos que essas atividades e seus efeitos, que perduram para além das visitas, consistem 
em recursos pedagógicos inovadores e relevantes para sua formação, além de contribuírem para a manutenção da saúde e equilíbrio emocional dos estudantes, muitas vezes afetados pelas pressões a que são expostos.

As impressões exteriorizadas por esses estudantes nos falam de encontros muito especiais, envoltos em emoções, música, cor, sorrisos e, às vezes, lágrimas, e que ocorrem num ambiente habitualmente frio e sem cor. Mesmo a vivência da morte é relatada com tons de suavidade.

Encontros que certamente contribuem para formar profissionais de saúde mais sensíveis e habilitados para lidarem com a complexidade do ser humano e com a complexidade da saúde humana.

\section{Colaboradores}

Os autores trabalharam juntos em todas as etapas de produção do manuscrito.

\section{Referências}

AYRES, J.R.C.M. Hermenêutica e humanização das práticas de saúde. Cienc. Saude Colet., v.10, n.3, p.549-60, 2005.

. O cuidado, os modos de ser (do) humano e as práticas de saúde. Saude Soc.,

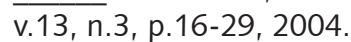

BONDÍA, J.L. Notas sobre a experiência e o saber da experiência. Rev. Bras. Educ., v.26, n.9, p.20-9, 2002.

BRASIL. Ministério da Saúde. Política Nacional de Humanização - Humaniza SUS. Brasília: Ministério da Saúde, 2004.

ESPINOZA, B. Ética. Belo Horizonte: Autêntica, 2009.

FERREIRA, J. O Programa de Humanização da Saúde: dilemas entre o relacional e o técnico. Saude Soc., v.14, n.3, p.111-8, 2005.

GARCIA, M.A.A. et al. A interdisciplinaridade necessária à educação médica. Rev. Bras. Educ. Med., v.31, n.2, p.147-55, 2007.

HENNINGTON, E.A. Acolhimento como prática interdisciplinar num programa de extensão universitária. Cad. Saude Publica, v.21, n.1, p.256-65, 2005.

KOIFMAN, L. O modelo biomédico e a reformulação do currículo médico da Universidade Federal Fluminense. Hist. Cienc. Saude - Manguinhos, v.8, n.1, p.48-70, 2001.

MINAYO, M.C.S. O desafio do conhecimento: pesquisa qualitativa em saúde. São Paulo: Hucitec, 2006.

POPE, C.; MAYS, N. Pesquisa qualitativa na atenção à saúde. Porto Alegre: Artmed, 2009.

REGO, S.; GOMES, A.P.; SIQUEIRA-BATISTA, R. Bioética e humanização como temas transversais na formação médica. Rev. Bras. Educ. Med., v.32, n.4, p.482-91, 2008.

RUIZ-MORAL, R. Relación médico-paciente: desafíos para la formación de profesionales de la salud. Interface - Comunic., Saude, Educ., v.11, n.23, p.619-35, 2007. 
SADALA, M.L.A.; SILVA, M.P. Cuidar de pacientes em fase terminal: a experiência de alunos de medicina. Interface - Comunic., Saude, Educ., v.12, n.24, p.7-21, 2008.

SANT'ANNA, D. Pacientes e passageiros. Interface - Comunic., Saude, Educ., v.4, n.1, p.13-20, 2000.

SARAIVA, J.L. Papel da extensão universitária na formação de estudantes e professores. Brasília Med., v.44, n.3, p.220-5, 2007.

SAUPE, R.; BUDÓ, M.L.D. Pedagogia interdisciplinar: "educare" (educação e cuidado) como objeto fronteiriço em saúde. Texto Contexto Enferm., v.15, n.2, p.326-33, 2006.

SOUZA, W.S.; MOREIRA, M.C.N. A temática da humanização na saúde: alguns apontamentos para debate. Interface - Comunic., Saude, Educ., v.12, n.25, p.327-38, 2008.

SUCUPIRA, A.C. A importância do ensino da relação médico-paciente e das habilidades de comunicação na formação do profissional de saúde. Interface - Comunic., Saude, Educ., v.11, n.23, p.619-35, 2007

TAPAJÓS, R. Objetivos educacionais na pedagogia das humanidades médicas: taxonomias alternativas (campos de significado e competências). Rev. Bras. Educ. Med., v.32, n.4, p.500-6, 2008.

A introdução das artes nos currículos médicos. Interface - Comunic., Saude, Educ., v.6, n.10, p.27-36, 2002.

TORALLES-PEREIRA, M.L. et al. Comunicação em saúde: algumas reflexões a partir da percepção de pacientes acamados em uma enfermaria. Cienc. Saude Colet., v.9, n.4, p.1013-22, 2004.

TURINI, B. et al. Comunicação no ensino médico: estruturação, experiência e desafios em novos currículos médicos. Rev. Bras. Educ. Med., v.32, n.2, p.264-70, 2008. 
"Boa noite, bom dia HUAP!" é um Projeto de Extensão da Universidade Federal Fluminense, cuja proposta é: contribuir para a humanização da formação na área de saúde, facilitando a integração de estudantes de diferentes cursos, a aquisição de competências comunicacionais, capacidade para cuidar e melhor lidar com a afetividade; contribuir para a recuperação e melhor qualidade do período de hospitalização de clientes do Hospital Universitário Antônio Pedro. São realizadas três intervenções por semana nas enfermarias, ocasiões em que os participantes são estimulados a interagir com a clientela por meio do diálogo e de atividades lúdicas criativas. Este trabalho avalia a contribuição do projeto na formação dos estudantes mediante os significados atribuídos pelos mesmos a essa experiência. Os relatos mostram que, apesar das dificuldades iniciais para lidar com sentimentos e emoções, as atividades têm proporcionado aos estudantes experiências consideradas gratificantes e importantes para sua formação.

Palavras-chave: Humanização. Formação de recursos humanos. Saúde. Extensão.

\section{"Good evening, good morning HUAP!", an experience of humanization within training for healthcare professionals}

"Good evening, Good morning HUAP!" is an extension project at Universidade Federal Fluminense in which the aim is to contribute towards humanizing training within healthcare through facilitating integration between students on different courses, acquisition of communication skills and capacity to care for and cope better with feelings and emotions. This will contribute towards recovery and better quality of hospital stay among patients at the Antônio Pedro University Hospital. Three interventions are made in the wards every week and, on these occasions, the participants are encouraged to interact with the clientele through dialogue and creative play activities. This study evaluated the contribution of the project towards the students' training, by analyzing the meanings that they ascribe to this experience. The reports showed that, despite the initial difficulties in dealing with feelings and emotions, the activities provided the students with experiences that they considered to be rewarding and important for their training.

Keywords: Humanization. Human resources development. Healthcare. Extension.

\section{"iBuenas noches, buenos días HUAP!", una experiencia de humanización en la formación de profesionales del área de salud}

"ïBuenas noches, Buenos días HUAP!" es un Proyecto de Extensión de la Universidad Federal Fluminense en el estado de Rio de Janeiro, Brazil, cuya propuesta es: contribuir para la humanización de la formación en el área de la salud, facilitando la integración de estudiantes de diferentes cursos, la adquisición de competencias de comunicación, capacidad para cuidar y tratar mejor con la afectividad; contribuir para la recuperación y mejor calidad del periodo de hospitalización de clientes del Hospital Universitario Antonio Pedro. Se realizan tres intervenciones por semana en las enfermarías, ocasiones en que se estimula a los pacientes a interaccionar con la clientela por medio del diálogo y de actividades lúdicas creativas. Este trabajo evalúa la contribución del proyecto en la formación de los estudiantes mediante los significados que ellos atribuyen a esta experiencia. Los relatos muestran que, a pesar de las dificultades iniciales en tratar con sentimientos y emociones, las actividades han proporcionado a los estudiantes experiencias consideradas gratificantes e importantes para su formación.

Palabras clave: Humanización. Formación de recursos humanos. Salud. Extensión. 
